\title{
Study on the stress path dependency of collapse behavior of Gorgan loess implementing unsaturated oedometer devices
}

\author{
S. Mohsen Haeri ${ }^{1, a}$, Majid Beigi $^{2}$, Saeed Saberi ${ }^{2}$ and Amir Akbari Garakani ${ }^{3}$ \\ ${ }^{1}$ Professor, Department of Civil Engineering, Sharif University of Technology, Tehran, Iran \\ ${ }^{2}$ M.Sc, Department of Civil Engineering, Sharif University of Technology, Tehran, Iran \\ ${ }^{3}$ Ph.D, Department of Civil Engineering, Sharif University of Technology, Tehran, Iran
}

\begin{abstract}
Collapsible soils such as loess are particular types of problematic soils, whose collapse potential have caused severe damages to the buildings and structures. Loess is susceptible to large and sudden volume reduction upon wetting in constant normal stress or upon increasing normal stress in constant water content or a combination of these two stress paths. In this research both of these collapse induced paths: wetting and stress paths are investigated on undisturbed specimens of a Loess to observe the effect of various parameters on the collapse behavior of the tested soil., Seven controlled matric suction unsaturated oedometer tests have been conducted on undisturbed specimens taken from loessial soil of Gorgan, a city in Golestan province in Iran to study the collapse mechanisms of this type of soils. Two identical sets of unsaturated oedometer apparatuses designed and developed at Sharif University of Technology, with the capability of controlling matric suction have been utilized. In these tests, the matric suction, vertical net stress, volumetric water content, and vertical deformation of the samples have been controlled and recorded. Tests have been performed under two separate stress paths: constant matric suction with varying vertical net stress (loading and unloading) and constant vertical net stress with varying matric suction (wetting and drying). Obtained results show the high collapse potential of the tested soil and significant effects of stress path, matric suction, and vertical net stress on the collapse behavior of the tested soil.
\end{abstract}

\section{Introduction}

Collapsible soils are known as soils with open and metastable structures. Increase of water content in normal and expansive soils leads to increase in volume or expansion, whereas in soils with open and metastable structure it leads to collapse if enough stress is applied on the soil as well. Most researchers [e.g. 1-4] suggest four for collapse in a soil: 1. An open- metastable and unsaturated fabric 2. A required bonds or cementing agent and/or suction for stability in unstructured state 3 . A required net total vertical stress for triggering metastable condition 4. An increase in water content, which subsequently results in collapse or sudden reduction of volume of the soil mass. Unlike the saturated soils, unsaturated soils have three phases: air, water and soil skeleton. The behaviors of unsaturated soils in general appear to be relatively complex in comparison to those of fully saturated soils. Since 1950's, significant developments have been made in understanding unsaturated soil behavior. Early attempts were aimed at treating unsaturated soil behavior in terms of a single effective stress parameter [5]. Jennings and Burland [6] recognized the limitation of this approach, and study the unsaturated behavior with total stress and suction variables which later led to the independent stress framework. Subsequently, many researchers proposed the

\footnotetext{
a Corresponding author: smhaeri@sharif.edu
}

frameworks in terms of two independent stress variables, net stress $\left(\sigma-u_{a}\right)$ and matric suction $\left(u_{a}-u_{w}\right)$ [7]. One of the most widely used elasto-plastic frameworks was first proposed by Alonso [8] as Barcelona model. This type of framework was unable to predict some behavior observed in the laboratory, for example, coupled hydro-mechanical soil response under drying/wetting cycles and influence of these cycles on subsequent behavior. More recent approaches [e.g. 9, 10] shifted towards a new choice of stress variables, which have implemented the corporation of both suction and degree of saturation to the soil grain stability and to the effective stress, similar to the original Bishop [5] approach. Later some other researchers proposed different models to describe the behavior of unsaturated soils [e.g. 11-13]. In brief, a variety of frameworks have been proposed for modelling of the behavior of unsaturated soils, most of which are still at the stage of development, and thus need experimental validation.

Based on observations on the experimental results presented in this research and some other studies [14-22], stress path dependency is one of the major aspects of the behavior of collapsible soils and a model or framework capable of predicting such behavior is needed. In this paper the hydro-mechanical stress path dependency of tested loess is highlighted, however, the framework for 
modelling such behavior is out of the scope of this paper and will be discussed elsewhere.

In this regard, two sets of suction-controlled oedometer apparatuses implementing axis-translation method [23] have been developed at Sharif University of Technology (SUT) and used to study the behavior of undisturbed specimens of highly collapsible loessial samples taken from a semi-arid region in Iran, Gorgan [14].

\section{Tested Soil Properties}

The studied soil in this research is a loessial soil taken intact in waxed monolithic boxes from the city of Gorgan in Golestan province of Iran. The oedometer undisturbed specimens with $2 \mathrm{~cm}$ height and $5 \mathrm{~cm}$, diameter have been taken from the intact samples. For more information the reader is referred to $[15,16]$. The soil is mainly silt size and the soil index tests reveal that the tested soil is ML in accordance with Unified Soil Classification System (USCS). Some other index properties of the tested soil are listed in Table 1.

As presented in Table 1. The average value of the initial degree of saturation of the tested soil is about $25 \%$. This value corresponds to an initial matric suction of 750 $\mathrm{kPa}$ according to the results of filter paper tests performed on this soil.

\section{Unsaturated Oedometer Devices}

To study the complex behavior of the collapsible soils in unsaturated soil mechanics framework, two oedometer devices with capability of controlling matric suction implementing axis translation method [23] have been designed, built and utilized in Advanced Soil Mechanics Laboratory of SUT as sketched in Figure 1.

In this research a $5 \mathrm{~cm}$ diameter high air entry value ceramic disk (HAEV) was fixed to the base of the oedometer cell and de-aired water pressure has been applied to the bottom of the HAEV disc. Monitoring of the height of the water column in the burette interconnected to this system specifies the absorbed or desorbed water to or from the specimens during the test. The require air pressure has been applied with vent on the top cap to keep the matric suction under control. The changes in the height of the specimen have been controlled with a strain gauge fixed at the top of the cap of the specimen (Figure 1).

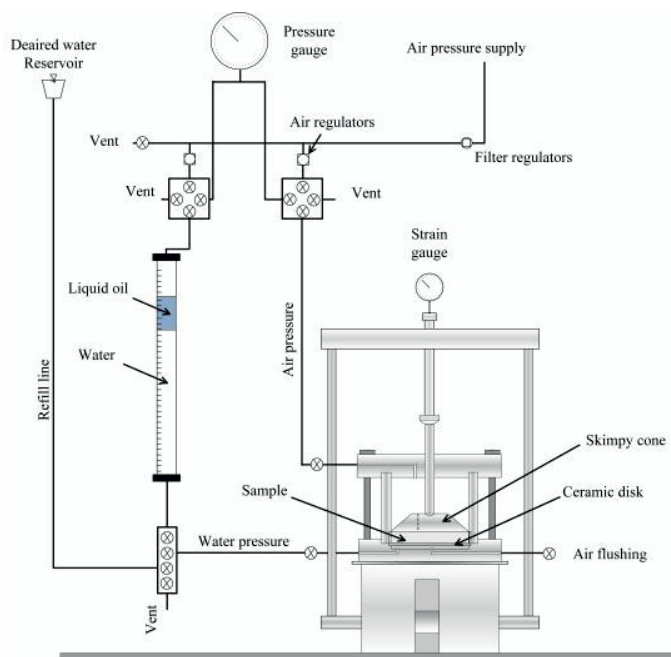

Figure 1. The schematic picture of the modified oedometers

\section{Stress and Wetting Paths and Test Procedures}

In order to investigate the collapsibility and stress-suction paths dependency of the experiments in addition to the mechanical behavior of the tested loess, a total of seven tests, in two groups: 1) constant matric suction under varying vertical net stress (loading and unloading) which has been named as vertical compression induced collapse tests, and 2) constant vertical net stress under varying matric suction (wetting and drying) which has been named as wetting induced collapse tests have been performed. The sitting load of $25 \mathrm{kPa}$ has been applied to the samples at the beginning of each test to reach to the required initial matric suction before taking any step toward the designed stress path. The stress path of each test is shown in Figure 2. During the tests the volume change and the amount of absorption (or desorption) of water for each specimen have been monitored.

\section{The Tests Results}

A summary of the tests results are shown in the following sections. Both variations of specific volume and degree of saturation of the specimens in each stress path versus vertical net stress and matric suction are presented and analyzed in Figures 3 and 4. In order to achieve the suction equilibrium within the specimens, each vertical compression induced collapse test lasted about 25-45 days and each wetting induced collapse test lasted about 65-75 days.

Table 1. Index properties of the selected "undisturbed" loessial soil specimens.

\begin{tabular}{|c|c|c|c|c|c|c|c|c|c|c|}
\hline & $\begin{array}{l}\text { Initial } \\
\text { void } \\
\text { ratio }\end{array}$ & $\begin{array}{l}\text { Initial } \\
\text { dry unit } \\
\text { weight }\end{array}$ & $\begin{array}{l}\text { Initial } \\
\text { moisture } \\
\text { content }\end{array}$ & $\begin{array}{c}\text { Initial } \\
\text { degree of } \\
\text { saturation }\end{array}$ & $\begin{array}{l}\text { Pass } \\
\text { no. } 4 \\
\text { sieve }\end{array}$ & $\begin{array}{c}\text { Pass } \\
\text { no. } 200 \\
\text { sieve }\end{array}$ & $\begin{array}{c}\text { Clay } \\
\text { Frac } \\
(<2 \mu \mathrm{m})\end{array}$ & \multicolumn{2}{|c|}{ Atterberg limits } & \multirow[t]{2}{*}{ USCS } \\
\hline & $\mathrm{e}_{\mathrm{o}}$ & $\gamma_{\mathrm{do}}\left(\mathrm{kN} / \mathrm{m}^{3}\right)$ & $\mathrm{w}_{\mathrm{o}}(\%)$ & $\mathrm{S}_{\mathrm{ro}}$ & $\mathrm{d}_{4}(\%)$ & $\mathrm{d}_{200}(\%)$ & $\mathrm{d}_{\mathrm{c}}(\%)$ & $\mathrm{W}_{\mathrm{L}}(\%)$ & $\mathrm{w}_{\mathrm{p}}(\%)$ & \\
\hline Avg & 0.76 & 15.09 & 7 & 0.25 & 100 & 96.5 & 26 & 32.7 & 25.5 & \multirow{2}{*}{ ML } \\
\hline Stnd. dev. & 0.006 & 0.005 & 0.119 & 0.005 & 0 & 1.1 & 3.3 & 0.3 & 0.8 & \\
\hline
\end{tabular}




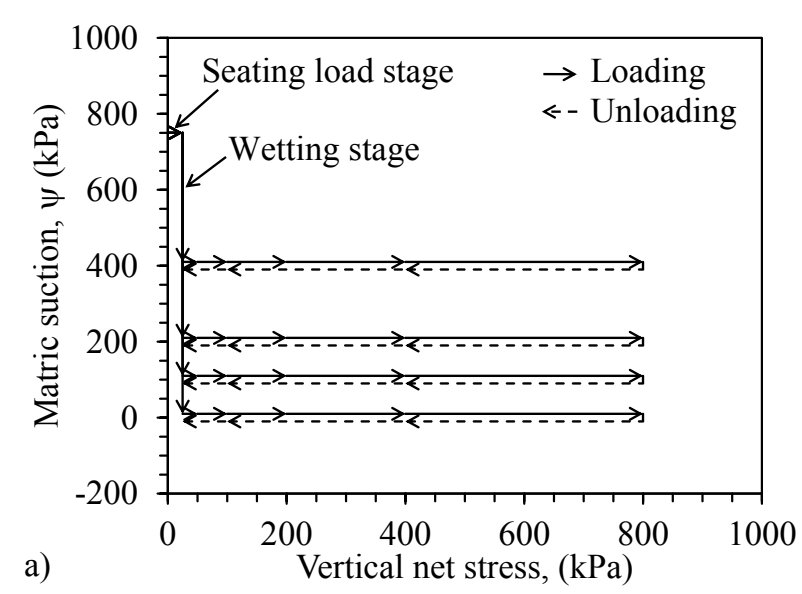

a)

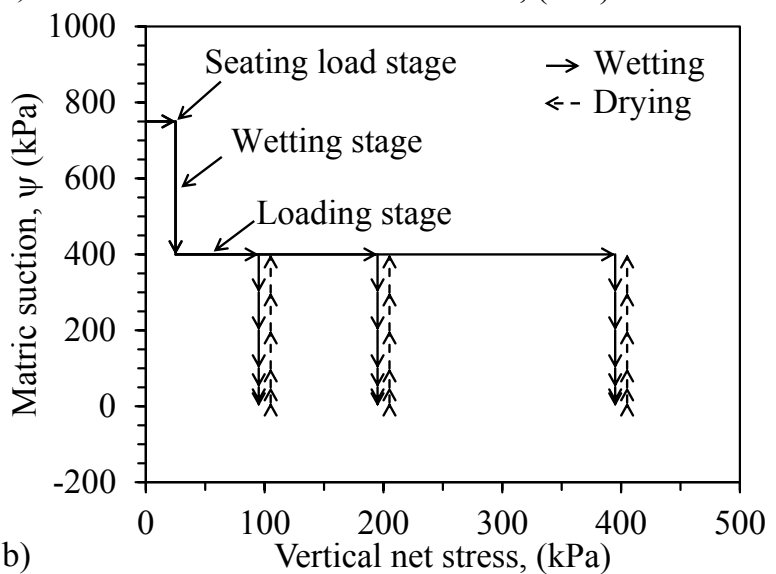

Figure 2. Applied loading stages used for testing of collapsible soils: a) vertical compression induced collapse tests at different constant matric suctions and b) wetting-induced collapse tests at different constant vertical net stresses.

\subsection{Stress Variables}

The variations of specific volume $(v)$ versus vertical net stress $\left(\mathrm{P}_{\mathrm{vn}}\right)$ corresponding to the vertical compression induced collapse tests are depicted in Figure 3.a. $\mathrm{P}_{\mathrm{vn}}$ (vertical net stress) is obtained from the Equation 1, where $P_{v}$ is the total vertical stress, $u_{a}$ is the air pressure and $\psi$ is the matric suction which is defined in Equation 2 , in which $u_{w}$ is the pore water pressure. The variation of specific volume with matric suction in the wetting induced collapse tests are presented in Figure 4.a as well:

$$
\begin{gathered}
p_{v n}=p_{v}-u_{a} \\
\psi=u_{a}-u_{w}
\end{gathered}
$$

\subsection{Vertical Compression Induced Collapse Tests}

The changes in specific volume of the specimens in vertical compression induced collapse tests are plotted against vertical net stress for both loading and unloading paths in Figure 3.a. Yield stress in these figures is defined as the stress in which significant volume change or collapse starts to take place in loading paths. As presented in Figure 3.a the amounts of change in specific volume before the yield point are much smaller in tests with higher matric suctions than those for the tests with lower matric suctions. This mild slope of volume changes versus vertical net stress before yield point especially in dryer soils is indicative of strong bonds between the soil grains. These bonds will break at specified yield stress that is a function of applied matric suction. In tests with smaller matric suctions the yield stress has smaller values which represent the lower threshold stresses for the bond breakage in lower matric suctions. Other observation from the tests results is that the slope of compression curves is not unique for different matric suctions and depends on the value of the tested matric suction. This fact is true both in pre-collapse (before yield stress) and in main collapse (after yield stress) stages of the tests meaning that the soil behaves elasto-plastic in both parts of the loading path. In other words, the behavior of collapsible soil in compression is neither elastic nor unique before pre-compression pressure (yield stress).

The changes of the degree of saturation with vertical net stress are presented in Figure 3.b for vertical compression induced collapse tests. As can be observed, in loading stage, the degrees of saturation of the specimens increase with increase in vertical net stress because of the pore collapse and reduction in pore size, especially after the yield stress.
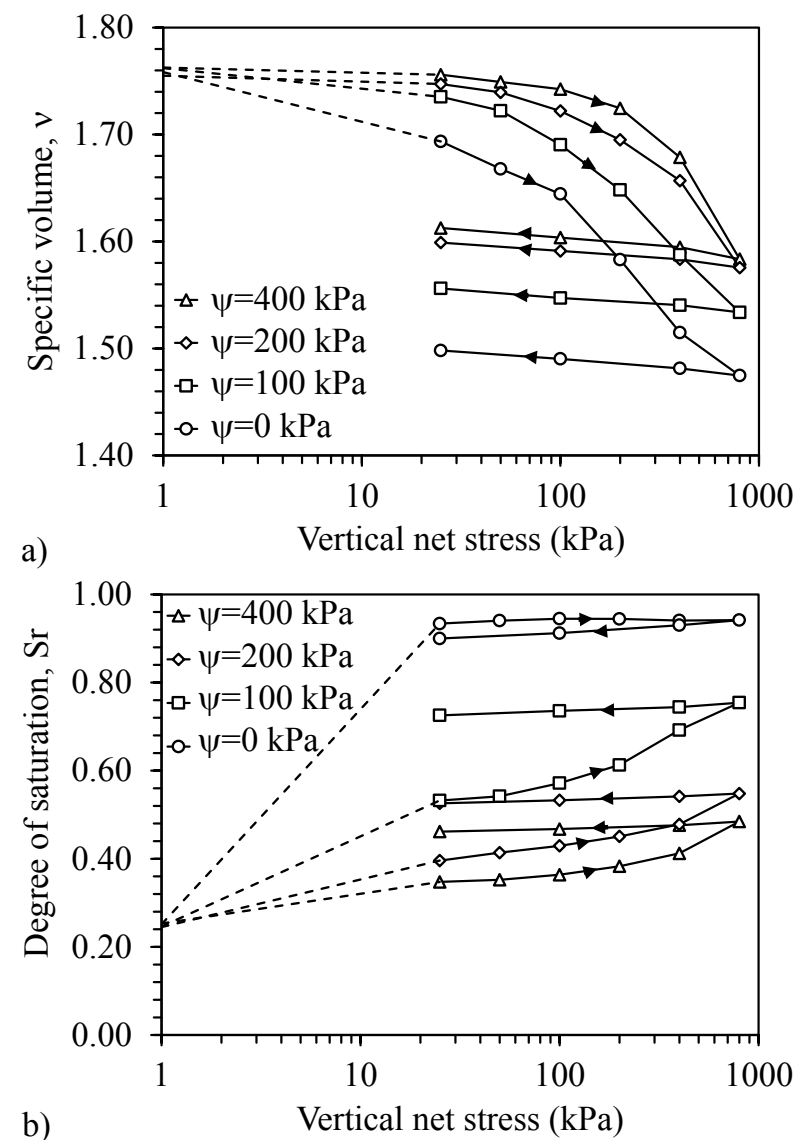

Figure 3. Results of vertical compression induced collapse tests conducted at different matric suctions: (a) specific volume as a function of applied vertical net stress, and (b) degree of saturation as a function of applied vertical net stress.

In unloading steps no significant decrease in degree of saturation happens because the volume reduction due to collapse is unrecoverable and the soil behaves elastically at this stage. 


\subsection{Wetting Induced Collapse Tests}

In Figure 4.a. the changes in specific volume of the wetting induced collapse tests have been plotted for various applied matric suctions. The initial specific volume and matric suction for all specimens is a point which is shown in the figure with a cross symbol. The initial changes in specific volume for reaching to the start of each test at $\psi=400 \mathrm{kPa}$ for various vertical net stresses are shown by dashed lines in Figure 4.a as well. In the main part of the tests which starts from $\psi=400 \mathrm{kPa}$ the matric suction decreases (wetting path) under constant vertical net stresses to get to the saturation state and then drying path is followed as shown by arrows in this figure.
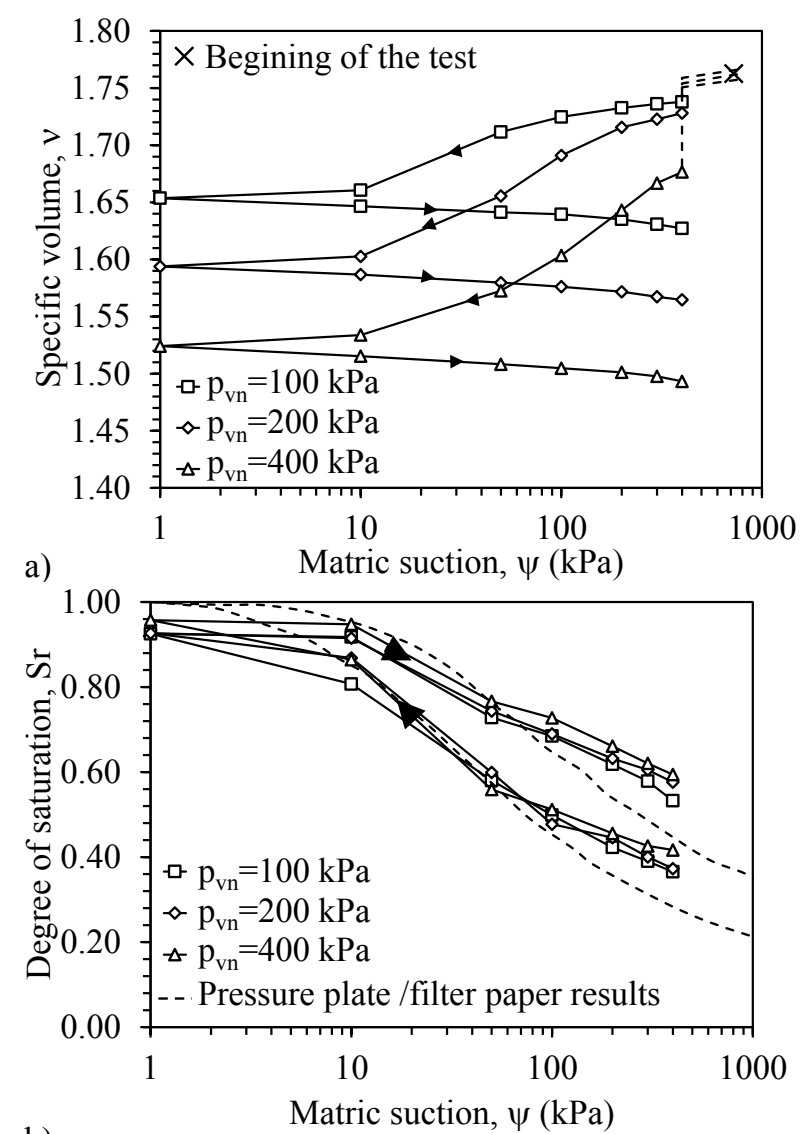

b)

Figure 4. Results of wetting-induced collapse tests conducted at different vertical net stress values: (a) specific volume as a function of the applied matric suction, and (b) degree of saturation as a function of the applied matric suction.

Three stages can be observed both in wetting path. In the first stage of wetting, volume reduction occurs with a gentle slope. We name this part as Pre-collapse stage. However, after a specific matric suction under a specific vertical net stress the slope of the volume change increases drastically. This part can be called as the main collapse stage. The matric suction in which the drastic change in the volume or main collapse starts is called as the "yield point" which increases with increase in the applied constant vertical net stress. When the main collapse takes place under a specific net stress with decreasing suction, the third stage starts and the slope of the volume change will significantly decrease which in turn results in small volume reduction with further wetting or decrease in matric suction. The drying path which follows the wetting path will cause very small additional volume reduction which can be related to increase in effective stress due to increase in matric suction during drying process. This fact indicates that the collapse associated with wetting path or wetting induced collapse is not recoverable with drying.

The changes in the degree of saturation with matric suction or SWRC for wetting induced collapse tests on the tested loessial soil, under various vertical net stresses, are presented in Figure 4.b. As shown in this figure, the SWRCs are very similar for different values of vertical net stresses and are very close to the SWRC of tested loess using filter paper, shown in the figure by dashed lines, especially in low to medium matric suctions. However the SWRCs resulted from wetting induced collapse oedometer tests on the tested collapsible soil for matric suctions of $100 \mathrm{kPa}$ and more deviate from the SWRC obtained from filter paper that is measured under zero effective stress [16].

\subsection{The Hydro-mechanical Stress Path Dependency of the Collapse Behavior}

So far the results shown and discussed in sections 5.2 and 5.3 clearly indicate the hydro-mechanical stress and stress path dependency of the tested collapsible soil. In the following, this fact is more elaborated. The results of the same stress states obtained from vertical compression induced collapse and wetting induced collapse tests are presented as variation of volumetric strain with matric suction in Figure 5.

As shown in this figure, the amounts of volumetric strains for wetting induced collapse tests are smaller than those for vertical compression induced collapse tests. The exception is the point associated with $\psi=200 \mathrm{kPa}$ in vertical compression induced collapse tests for which the reason is not known and can be an experimental error. These differences are more significant in the middle or main collapse parts of the paths. However, at high matric suction values the soil structure is more stable and has stronger bonds which make the volume changes more independent to the applied stress and wetting paths. Also at matric suction values near the saturation state, most of the bonds have been broken and the volumetric strain due to bond breakage meaning that at low matric suctions the behavior is less path dependent.

The variation in degree of saturation against matric suction (SWRC) of the specimens of both group of tests are plotted in Figure 6 as well. The inter-related behavior of the variation of degree of saturation and volumetric strain is noticeable in Figures 5 and 6. The amounts of volumetric strain of specimens in wetting induced collapse tests for a particular matric suction is smaller than that for vertical compression induced collapse tests as discussed above and shown in Figure 5. However, the degree of saturation at that particular matric suction would be larger for the specimen tested following the vertical compression induced collapse compare to that tested under wetting induced collapse condition as can be 
observed from Figure 6. The variation of the slopes of the curves given in Figures 5 and 6 are closely linked as well.
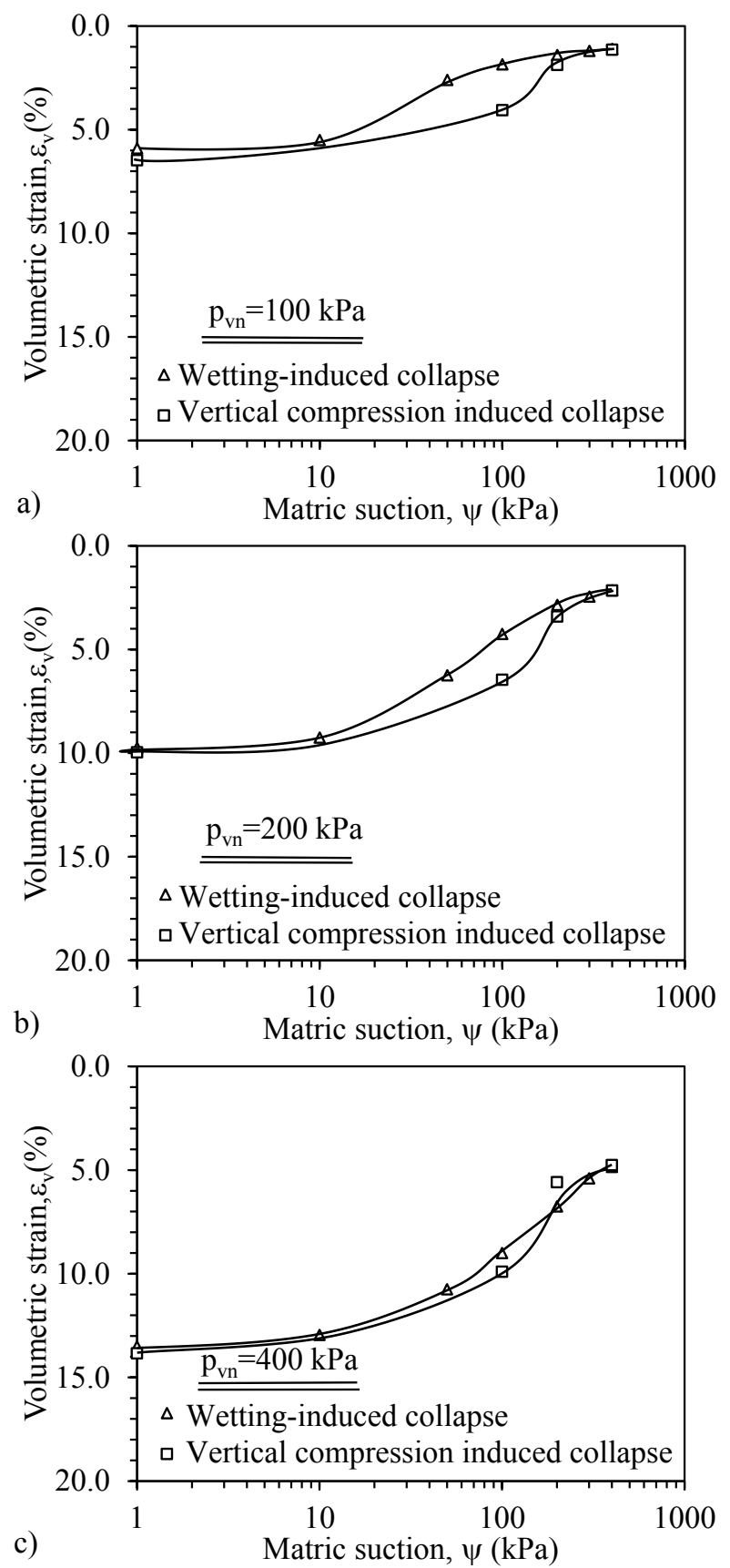

Figure 5. Comparison of volumetric strain as a function of applied matric suction in vertical compression induced collapse and wetting-induced collapse tests on tested loess at vertical net stresses of a) $100 \mathrm{kPa}$, b) $200 \mathrm{kPa}$ and c) $400 \mathrm{kPa}$

\subsection{Stress and Stress Path Dependency of the SWRC}

The SWRCs for various compression induced collapse tests are calculated from the test results and are given in Figure 7. As can be observed from SWRCs are not unique and are completely stress dependent. Also there is no match between SWRC obtained from filter paper under Zero stress and those obtain by compression induced collapse tests at various vertical net stresses.
Stress path dependency of SWRC for the tested collapsible soil is obvious when the results shown in Figure 7 is compared with that shown in Figure 5.b which is the SWRC curves for the same soil tested under wetting induced collapse path.
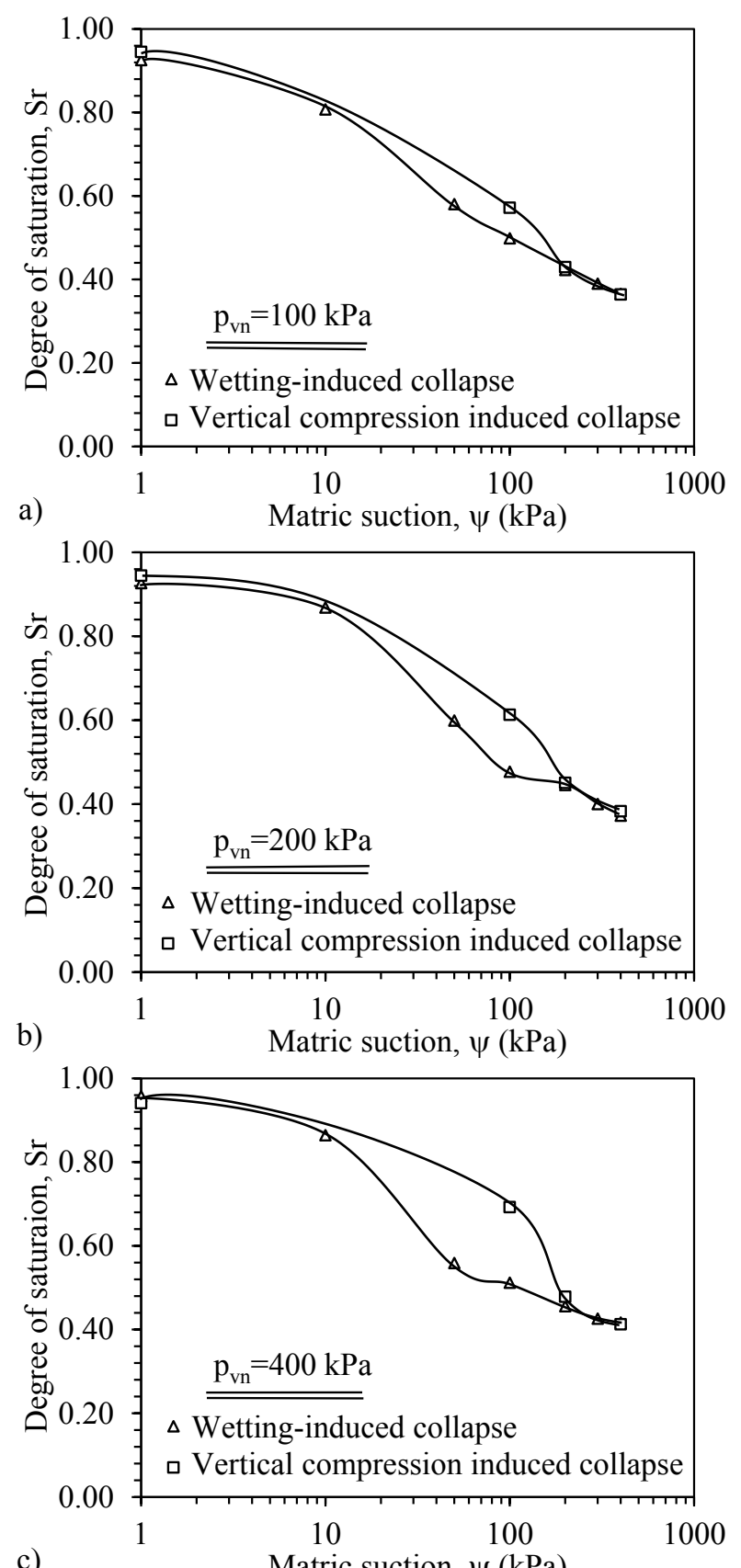

c) Matric suction, $\psi(\mathrm{kPa})$

Figure 6. Comparison of degree of saturation as a function of the applied matric suction from vertical compression tests and wetting-induced collapse tests at vertical net stresses for a) 100 , b) 200 and c) $400 \mathrm{kPa}$

If the result shown in Figure 5.b which are the SWRC curves for wetting induced collapse tests implementing unsaturated oedometer devices, are compared with the SWRCs obtained from wetting induced collapse tests on the same soil, using triaxial device under isotropic compression $[15,16]$, one can observe the differences between these two cases. The reason could be difference in stress states. During tests on specimens using 
oedometer device an intrinsic shear stress is induced in the specimen due to $\mathrm{k}_{\mathrm{o}}$ condition, whereas in triaxial compression tests the soil is under an isotropic pressure with zero shear stress. This fact emphasizes the stress path dependency of the unsaturated behavior of collapsible soils.

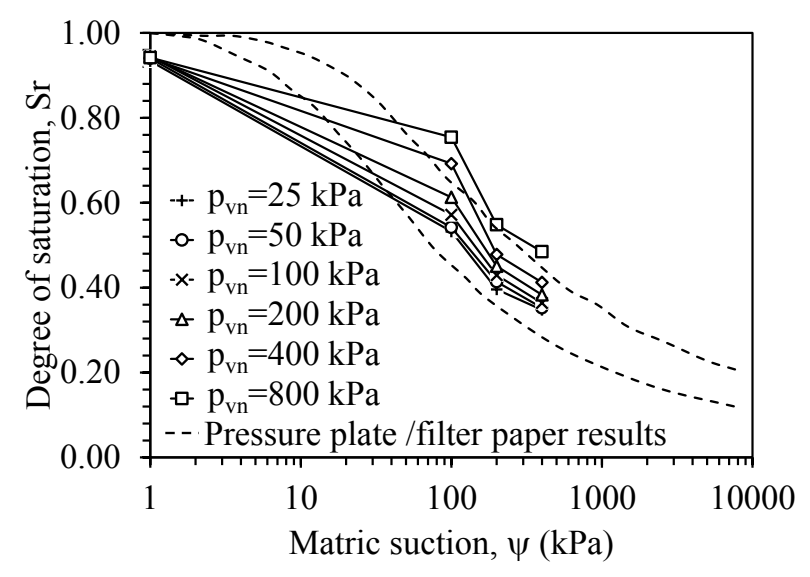

Figure 7. SWRC which has obtained from vertical compression tests results

\section{Conclusions}

In this study, the hydro-mechanical behavior of a collapsible loessial soil is investigated by conducting unsaturated odometer tests under applying two different stress paths namely, "vertical compression induced collapse tests" and "wetting induced collapse tests". Results of the vertical compression induced collapse tests reveal that collapsible behavior of the tested soil is elastoplastic throughout the loading stage. Also it is shown that the yield stress of the soil during vertical compression induced collapse tests, increases by increasing the matric suction. In the same line, in wetting induced collapse tests, by increasing vertical net stress the value of the yield point of the soil increases. Also it is observed that the dependency of the hydro-mechanical behavior of the tested soil to the stress path is more profound for the middle parts of the wetting induced collapse tests where main collapse of the structure of the soil happens in this part. For both types of the applied stress path, the SWRCs of the soil are highly dependent on the level of applied matric suction and the amount of vertical net stress.

\section{References}

1. L. Barden, A. O. Madedor, G. R. Sides. J Soil Mech Found Div, ASCE 95, 33-51 (1969)
2. J. H. Dudley. J Soil Mech Found Div 97, (1900)

3. L. Barden, A. McGown, K. Collins. Engineering Geology 7.1, 49-60 (1973)

4. J. K. Mitchell, K. Soga. New York: Wiley 422 (1976)

5. A. W. Bishop. Teknisk Ukeblad I Samarbeide Med Teknikk, 39, 859-863 (1959)

6. J. E. B. Jennings, J. B. Burland. Geotechnique 12, 125-144 (1962)

7. D. G. Fredlund, H.Rahardjo. John Wiley \& Sons (1993)

8. E. Alonso, A. Gens, A. Josa, Geotechnique, London, 40(3), 405-430 (1990)

9. S. J. Wheeler, R. S. Sharma, M. S. R. Buisson. Geotechnique 53, 41-54 (2003)

10. D. Gallipoli, S. J. Wheeler, M. Karstunen. Geotechnique 53, 105-112 (2003)

11. D. G. Toll. Geotechnique 40, 31-44 (1990)

12. J. A. Blatz, J. Graham. Geotechnique 53, 113122 (2003)

13. N. Khalili, F. Geiser, G. E. Blight. International Journal of Geomechanics 4.2, 115-126 (2004)

14. M. Beigi. M.Sc. thesis, Sharif University of Technology, Tehran, Iran (2015)

15. A. A. Garakani. Ph.D. thesis, Department of Civil Engineering, Sharif University of Technology, Tehran, Iran (2013)

16. S. M. Haeri, A. A. Garakani, A. Khosravi, C. L. Meehan. ASTM, Geotechnical Testing Journal, 37(2) (2014)

17. S. M. Haeri, A. A. Garakani. Research and Applications. Springer Berlin Heidelberg, 293300 (2012)

18. S. M. Haeri, S. Saberi, M. Beigi, A. A. Garakani. 15th Pan-American Conference on Soil Mechanics and Geotechnical Engineering, Buenos Aires, Argentina, (2015)

19. S. M. Haeri, A. Khosravi, A. A. Garakani, S. Ghazizadeh. ASCE, International Journal of Geomechanics (under review) (2016)

20. S. M. Haeri. 15th Asian Regional Conference on Soil Mechanics and Geotechnical Engineering, Fukuoka, Japan (2015)

21. S. M. Haeri, A. A. Garakani. 15th Asian Regional Conference on Soil Mechanics and Geotechnical Engineering, Fukuoka, Japan (2015)

22. A. A. Garakani, S. M. Haeri, A. Khosravi, G. Habibagahi. Engineering Geology 195, 28-41 (2015)

23. J.W. Hilf. Ph.D. thesis, University of Colorado Boulder, Boulder, CO, USA. (1956) 